\title{
Menstrual hygiene practices in young girls of urban India
}

\author{
Reena V. Wagh¹, Aditi J. Upadhye², Jayshree J. Upadhye ${ }^{3 *}$
}

\author{
${ }^{1}$ Department of Biochemistry, Government Medical College, Nagpur, India \\ ${ }^{2}$ Department of Pathology, Dr. Panjabrao Deshmukh Memorial Medical College, Amravati, Maharashtra, India \\ ${ }^{3}$ Department of Obstetrics and Gynecology, Rajshree Medical college, Bareilly, Uttar Pradesh, India
}

Received: 08 March 2018
Accepted: 03 April 2018

\section{*Correspondence:}

Dr. Jayshree J. Upadhye,

E-mail: jayshreeupadhye@gmail.com

Copyright: $\odot$ the author(s), publisher and licensee Medip Academy. This is an open-access article distributed under the terms of the Creative Commons Attribution Non-Commercial License, which permits unrestricted non-commercial use, distribution, and reproduction in any medium, provided the original work is properly cited.

\begin{abstract}
Background: Menstrual hygiene is an important aspect in the life of young girls. The present study aims at assessing the knowledge regarding menstruation and hygienic practices and perceptions during menstruation.

Methods: It was a cross sectional study, conducted among 100 young girls of 20-22 years age to assess the awareness of menstrual hygiene. Data was collected by pre-tested questionnaire. Statistics was calculated in percentages.

Results: Out of 100 girls, $71(71 \%)$ knew about menstruation before menarche while $29(29 \%)$ did not have any knowledge. 71 (71\%) girls knew the cause of menstruation as physiological, $18(18 \%)$ girls didn't know the cause, 11 $(11 \%)$ girls still believe it as curse of God. $68(68 \%)$ girls knew the source of bleeding during menstruation as uterus, $20(20 \%)$ girls thought it as vagina while $12(12 \%)$ thought it as urethra. $64 \%$ girls use sanitary pads during menstruation, $19 \%$ girls used old cloth while $17 \%$ girls used new cloth during menstruation as adsorbent material. $9 \%$ girls dispose pads or used cloth in dustbin, $19 \%$ girls flush them in toilet while $12 \%$ girls throw them roadside. $96 \%$ girls avoid going to temple, $68 \%$ girls restrict their daily activities, $56 \%$ girls avoid going to functions, $50 \%$ girls avoid going to kitchen, $50 \%$ girls avoid going to kitchen while $45 \%$ girls avoid touching things at home.

Conclusions: It is very important that young girls should be educated about the importance of maintaining hygiene during menstruation to prevent the risk of reproductive tract infections.
\end{abstract}

Keywords: Knowledge, Menstrual hygiene, Perception, Reproductive tract infections

\section{INTRODUCTION}

Menstruation is the visible manifestation of cyclic physiologic uterine bleeding because of shedding of uterine endometrium. Menarche occurs between 11-15 years. ${ }^{1}$ Sympathetic and careful handling of young girl experiencing menstruation is of paramount importance. It is done by mothers explaining the physiological changes during the period. ${ }^{2}$ Menstruation is generally considered as unclean and dirty in the Indian society.

Isolation during menstruation and restrictions being imposed on the girls in the family have created a negative attitude towards it. ${ }^{3}$ Menstrual Hygiene Management
(MHM) is defined as 'Women and adolescent girls using a clean material to absorb or collect mebstrual blood that can be changed in privacy as often as necessary for the duration of the menstruation period, using soap and water for washing the body as required, and having access to facilities to dispose of used menstrual management materials'. ${ }^{4}$

There is a substantial lack in the knowledge about menstruation among adolescent girls. Social inhibitions and the negative attitude of people in discussing the related issues openly, prevents the adolescent girls to the right kind of information, especially in the rural and tribal communities. Most of the adolescent girls had incomplete 
and inaccurate information about the menstrual physiology and hygiene.

Good hygienic practices like use of sanitary pads and adequate washing of the genital area are essential during menstruation. Women and girls of the reproductive age need access to clean and soft, absorbent sanitary pads which can protect their health. ${ }^{5}$

The reaction to menstruation depends upon awareness and knowledge about it. The manner in which a girl is educated about menstruation and its associated changes can have an impact on her response to the menarche. ${ }^{6}$ Although menstruation is a natural process; it is associated with several misconceptions and practices.

This sometimes results into adverse health outcomes. Hygiene related practices of women during menstruation are of considerable importance. Bad hygienic practices leads to increased vulnerability to reproductive tract infections. $^{7}$

The interplay of socio-economic status, menstrual hygiene practices and reproductive tract infections are noticeable.

Women having better knowledge of menstrual hygiene and safe practices are less vulnerable to reproductive tract infections and its consequences. ${ }^{8}$

Menarche is a milestone in a woman's life. It denotes the start of reproductive capacity. Unfortunately, there is gross lack of information on menstrual preparedness and management among adolescent girls.

This situation is made worse by the shyness and embarrassment with which discussions about menstruation is treated. ${ }^{9}$

Menstrual hygiene is a very important risk factor for reproductive tract infections. It is a vital aspect of health education for adolescent girls.

Television programmes for education, trained school nurses/health personnel, motivated school teachers and knowledgeable parents can play a very important role in transmitting the vital message of menstrual hygiene to the adolescent girl of today. ${ }^{10}$

Therefore, increased knowledge about menstruation right from childhood may escalate safe practices. It may help in decreasing the suffering of many women.

With this background the present study was conducted to assess the knowledge, beliefs, and source of information regarding menstruation among the young girls and also to identify the status of menstrual hygiene among them.

The Objectives of the present study are to assess the knowledge and practices of menstrual hygiene among urban young girls. to study cultural practices associated with menstrual hygiene, to assess the restrictions which were practiced by young girls during menstruation and to suggest recommendation based on study findings.

Table 1: Questionnaire.

\begin{tabular}{|c|c|c|c|}
\hline Variables & Answers & & \\
\hline Age in years & $<13$ years & 13-19 years & \\
\hline Use of adsorbent material & Sanitary pads & New cloth & Old cloth \\
\hline Do you follow taboos of menstruation & $\begin{array}{l}\text { Yes, if yes, mention } \\
\text { which taboo }\end{array}$ & No & \\
\hline $\begin{array}{l}\text { Did you receive information about menstruation before } \\
\text { menarche? }\end{array}$ & Yes & No & \\
\hline What was the source of information? & Mother/ Sister & $\begin{array}{l}\text { Relative/ } \\
\text { Teacher/ } \\
\text { Friend }\end{array}$ & $\begin{array}{l}\text { Radio/ TV/ } \\
\text { News paper }\end{array}$ \\
\hline Why do you get bleeding during menses? & Normal physiological & $\begin{array}{l}\text { Don't } \\
\text { know }\end{array}$ & Curse of god \\
\hline From which organ do the menstrual blood come? & Uterus & Urethra & $\begin{array}{l}\text { Vagina/ Don't } \\
\text { know }\end{array}$ \\
\hline How do you dispose it? & $\begin{array}{l}\text { Throw it in routine } \\
\text { waste }\end{array}$ & Bury & Flush \\
\hline Do you clean your genitals during menses? & Yes & No & \\
\hline Material used for cleaning genitalia & Water & $\begin{array}{l}\text { Water and } \\
\text { Soap }\end{array}$ & $\begin{array}{l}\text { Water and } \\
\text { antiseptics }\end{array}$ \\
\hline Do you take bath during menses? & Yes & No & \\
\hline
\end{tabular}




\section{METHODS}

\section{Study design}

A community based cross-sectional study was carried out amongst the young girls of 20-22 years age from urban areas of Nagpur district. Selection of girls was by random selection.

\section{Study period}

The present study was carried out during the period September to November 2017.

\section{Inclusion criteria}

- Girls who have attended menarche

- Girls who were willing to participate

\section{Exclusion criteria}

- Girls who were willing but unable to provide important information about menstruation and practices

Study was to be carried out with due permission of ethics committee. Permission from college authority was be sought before start of the study.

Verbal consent of the girls was obtained. Girls were asked about their knowledge of menstruation, awareness of menstrual hygiene and their perception about the taboos followed during menstruation. A predesigned, pretested, questionnaire was used for data collection. Data collection was done through person to person interview of study subjects by single female investigator.

\section{Taboos followed during menstruation}

Should not go to temple/ Should not enter the kitchen/ Separated during menses/should not touch plants/Restrict daily activities

Girls were told about the physiology of menstruation and menstrual morbidities. Advice was given about proper menstrual hygiene. Treatment was advised for anemia and menstrual morbidities. Girls were advised to seek medical advice when needed.

Data was entered in Microsoft excel sheet systematically. Categorical data was analyzed. Statistics was taken out in percentages for all the variables.

\section{RESULTS}

In the present study, out of 100 girls, 71 (71\%) knew about menstruation before menarche.
They knew about the approximate age of menarche, periodicity of menstrual cycle and care to be taken of menstrual bleeding. $29(29 \%)$ did not have any knowledge about menstruation (Table 2).

Table 2: Knowledge before menarche

\begin{tabular}{|lll|}
\hline Knowledge before menarche & No. of girls & $\%$ \\
\hline Yes & 71 & 71 \\
\hline No & 29 & 29 \\
\hline
\end{tabular}

In the present study, out of 100 girls, $71(71 \%)$ girls knew the cause of menstruation as physiological.

They knew that menstruation is the change in the body occurring in girls. They knew this change is necessary for the reproduction. $18(18 \%)$ girls didn't know the cause, $11(11 \%)$ girls still believe it as curse of God (Table 3).

Table 3: Cause of menstruation

\begin{tabular}{|lll|}
\hline Cause of menstruation & No. of girls & $\%$ \\
\hline Physiological & 71 & 71 \\
\hline Don't know & 18 & 18 \\
\hline Curse of God & 11 & 11 \\
\hline
\end{tabular}

In the present study, out of 100 girls, $68(68 \%)$ girls knew the source of bleeding during menstruation as uterus.

They knew that this cyclical change is due to hormonal changes. $20(20 \%)$ girls thought it as vagina while 12 $(12 \%)$ thought it as urethra (Table 4$)$.

Table 4: Source of bleeding during menstruation

\begin{tabular}{|c|c|c|}
\hline Source of bleeding during menstruation & $\begin{array}{l}\text { No. of } \\
\text { girls }\end{array}$ & $\%$ \\
\hline Uterus & 68 & 68 \\
\hline Vagina & 20 & 20 \\
\hline Urethra & 12 & 12 \\
\hline
\end{tabular}

In the present study, 64\% girls use sanitary pads during menstruation.

The girls using sanitary pads were from middle class and upper class and belong to educated families. $19 \%$ girls used old cloth while $17 \%$ girls used new cloth during menstruation as adsorbent material. These girls were from low socio-economic class (Table 5).

Table 5: Adsorbent used during menstruation

\begin{tabular}{|lll|}
\hline Adsorbent used during menstruation & $\begin{array}{l}\text { No. of } \\
\text { girls }\end{array}$ & $\%$ \\
\hline Sanitary pads & 64 & 64 \\
\hline Old cloth & 19 & 19 \\
\hline New cloth & 17 & 17 \\
\hline
\end{tabular}


In the present study, $69 \%$ girls dispose pads or used cloth in dustbin. These girls belong to educated families and were from upper and middle class. $19 \%$ girls flush them in toilet while $12 \%$ girls throw them roadside. (Table 6).

Table 6: Disposal of used pad

\begin{tabular}{|lll|}
\hline Disposal of used pad & No. of girls & $\%$ \\
\hline Throw in dustbin & 69 & 69 \\
\hline Flush in toilet & 19 & 19 \\
\hline Throw roadside & 12 & 12 \\
\hline
\end{tabular}

In the present study, $96 \%$ girls avoid going to temple, $68 \%$ girls restrict their daily activities, $56 \%$ girls avoid going to functions, $50 \%$ girls avoid going to kitchen, $50 \%$ girls avoid going to kitchen while $45 \%$ girls avoid touching things at home. These taboos were due to cultural environment at home (Table 7).

\section{Table 7: Restrictions during menstruation}

\begin{tabular}{|lll|}
\hline Restrictions during menstruation & No. of girls & $\%$ \\
\hline Avoid going to temple & 96 & 96 \\
\hline Restrict daily activities & 68 & 68 \\
\hline Avoid going to function & 56 & 56 \\
\hline Avoid going to kitchen & 50 & 50 \\
\hline Avoid going to college & 48 & 48 \\
\hline Avoid touching things at home & 45 & 45 \\
\hline
\end{tabular}

In the present study, source of information about menstruation in $62 \%$ was mother. Source of information was friend in 30\%, media like TV/radio/newspaper in 5\% and relative in $3 \%$ girls (Table 8 ).

Table 8: Source of information

\begin{tabular}{|lll|}
\hline Source of information & No. of girls & $\%$ \\
\hline Mother & 62 & 62 \\
\hline Friend & 30 & 30 \\
\hline TV/Radio/Newspaper & 5 & 5 \\
\hline Relative & 3 & 3 \\
\hline
\end{tabular}

\section{DISCUSSION}

In the present study, out of 100 girls, $71(71 \%)$ knew about menstruation before menarche while 29 (29\%) did not have any knowledge about menstruation.

In the present study, out of 100 girls, $71(71 \%)$ girls knew the cause of menstruation as physiological, $18(18 \%)$ girls didn't know the cause, 11 (11\%) girls still believe it as curse of God.

Dipanwita Pandit et al found that correct knowledge was found among 370(85.05\%) girls, while $15.04 \%$ associated it to disease or a curse of God. 315(72.41\%) girls had knowledge on menstruation before menarche.5
In the present study, out of 100 girls, 68 (68\%) girls knew the source of bleeding during menstruation as uterus, 20 (20\%) girls thought it as vagina while $12(12 \%)$ thought it as urethra.

Dipanwita Pandit et al., found that 178 (40.94\%) girls had the correct knowledge that uterus was the source of menstrual blood, while others said that it is urinary bladder $(8.27 \%)$, vagina $(45.74 \%)$ or abdomen $(5.05 \%)$. $222(51.03 \%)$ girls knew that pregnancy is the cause of missed period and $20(4.59 \%)$ girls did not know the cause. $^{5}$

Ray Sudeshna et al found that $42 \%$ of the girls had knowledge about menstruation before their onset of menarche, the main source of knowledge being mother and sister $(45 \%){ }^{9}$

Ray Sudeshna et al., found that $1 / 3$ of the population did not have the correct knowledge of the cause of menstruation and only $17.9 \%$ of the adolescent girls knew that uterus was the source of blood in menstruation. Majority $(62.6 \%)$ of the girls used only cloth as their menstrual absorbent. ${ }^{9}$

Dasgupta A et al found that Out of 160 respondents, 108 $(67.5 \%)$ girls were aware about menstruation prior to menarche. Mother was the first informant regarding menstruation in $60(37.5 \%)$ girls. $138(86.25 \%)$ girls believed it as a physiological process. ${ }^{10}$

P. Mary Moses et al found that $80 \%$ of the respondents knew about menstruation before menarche. In most cases predominant source of information was their mother. Only $82 \%$ knew that the bleeding occurs from uterus. ${ }^{11}$

In the present study, $64 \%$ girls use sanitary pads during menstruation, $19 \%$ girls used old cloth while $17 \%$ girls used new cloth during menstruation as adsorbent material.

P. Mary Moses et al., found that $78 \%$ of the respondents use sanitary napkins, $22 \%$ use cloth. $83 \%$ of the respondents change the napkin 2-3times per day. Cleaning of external genitalia during menstruation was present in all of the respondents. ${ }^{11}$

In the present study, $69 \%$ girls dispose pads or used cloth in dustbin, $19 \%$ girls flush them in toilet while $12 \%$ girls throw them roadside.

Tazeen Saeed Ali et al., found that $50 \%$ of the girls lacked knowledge of the origin of menstrual blood. Source of information was through conversations with their mothers.

Many reported being afraid at the first experience of bleeding. $50 \%$ reported that they did not take baths during menstruation. There were unhygienic practices 
and misconceptions among girls requiring action by health care professionals. ${ }^{12}$

Shobha P Shah et al found that $68 \%$ of adolescent girls said their first choice was falalin cloths. $32 \%$ said it was sanitary pads. None of them preferred old cloths. The introduction of falalin cloths improved quality of life significantly $(\mathrm{p}<0.000)$ and to a lesser extent also sanitary pads.

No significant reduction was observed in self-reported symptoms of reproductive tract infections. Falalin cloths were culturally more acceptable as they were readily available, easy to use and cheaper than sanitary pads. ${ }^{13}$

In the present study, $96 \%$ girls avoid going to temple, $68 \%$ girls restrict their daily activities, $56 \%$ girls avoid going to functions, $50 \%$ girls avoid going to kitchen, $50 \%$ girls avoid going to kitchen while $45 \%$ girls avoid touching things at home.

In the present study, source of information about menstruation in $62 \%$ was mother. Source of information was friend in $30 \%$, media like TV/radio/newspaper in $5 \%$ and relative in $3 \%$ girls.

Abdel-Hady et al found that the significant predictors of use of sanitary pads were availability of mass media at home, high and middle social class and urban residence. Mass media were the main source of information about menstrual hygiene, followed by mothers.

A large majority of girls said they needed more information. Information in menstrual hygiene should be linked to an expanded programme of health education in schools. A supportive environment for menstrual hygiene has to be provided both at home and in school. Sanitary pads made more affordable. ${ }^{14}$

Enu Anand et al found that only $15 \%$ of women used sanitary pad/locally prepared napkins during menstruation in India. Both RTI and Vaginal discharge were positively related with non-use of hygienic methods $(\mathrm{OR}=1.046, \mathrm{p}<0.001, \mathrm{CI}=1.021-1.071)$ and vaginal discharge $(\mathrm{OR}=1.303, \mathrm{p}<0.001, \mathrm{CI}=1.266-1.341) .{ }^{15}$

\section{CONCLUSION}

In the present study, there was good knowledge about menstruation, but they need more education about menstrual hygiene. A variety of factors affect menstrual behaviours.Amongst these, most influential is economic status and residential status whether urban or rural. It is essential to design a mechanism to address and for the access of healthy menstrual knowledge.

Institutionalizing sexuality education in schools; developing and disseminating sensitive adolescent reproductive health massages targeted to both parents as well as their adolescent children is most important. Also, access of the adolescents to youth friendly services should be improved.

It is very important that young girls should be educated about the importance of maintaining hygiene during menstruation to prevent the risk of reproductive tract infections. Taboos should be removed by healthy discussion. Focused care and counselling of these young patients would be a great investment for their and their families' future health and the society and nation as a large.

Funding: No funding sources

Conflict of interest: None declared

Ethical approval: The study was approved by the Institutional Ethics Committee

\section{REFERENCES}

1. World Health Organization. International Statistical Classification of Disease and Related Problem; 10th revision (ICD-10). Geneva: WHO:1992. Available from: www.cdc.gov/nchs/icd/icd10.htm. February, 2011.

2. Dasgupta A, Sarkar M. Menstrual hygiene: How hygienic is the adolescent girl? Indian J Commun Med. 2008;33:77-80.

3. Dhingra R, Kumar A. Knowledge and practices related to menstruation among tribal (Gujjar) adolescent girls, Etho-Med. 2009;3:43-8.

4. Shyam SB, Meika B, Enrique CS, Reshu AS, Menstrual hygiene management among women and adolescent girls in the aftermath of the earthquake in Nepal, BMC Women's Health BMC series- open, inclusive and trusted2018;18:33.

5. Dipanwita P, Prasanta KB, Raja B, Menstrual Hygiene: Knowledge and Practice among Adolescent School Girls In rural areas of West Bengal, IOSR J Dent Med Sci. 2014;3:19-24.

6. Rao S, Joshi S, Kanade A. Height velocity, body fat and menarcheal age of Indian girls. Indian Pediatr 1998; 35:619-28.

7. Singh MM, Devi R, Garg S, Mehra M. Effectiveness of syndromic approach in management of reproductive tract infections in women. Indian $\mathrm{J}$ Med Sci. 2001;55:209-14.

8. Wasserheit JN. The significance and scope of reproductive tract infections among Third World women. Int J Gynecol Obstet. 1989;3:145-68.

9. Ray S, Dasgupta A, determinants of menstrual hygiene among adolescent girls: a multivariate analysis, Nat J Commun Medi 2012;3:294-301.

10. Dasgupta A and Sarkar, Madhutandra.. Menstrual Hygiene: How Hygienic is the Adolescent Girl? Indian Journal of community medicine:Indian Association of Prevent Soc Medi. 2008;33:77-80.

11. Mary MP, Krishna BG, Menstrual Hygiene among Adolescent Girls: A Cross-sectional study in Government High School, Kakinada , East Godavari District, 
12. Tazeen SA, Syeda NR, Menstrual knowledge and practices of female adolescents in urban Karachi, Pakistan, J Adoles. 2010;33:531-41.

13. Shobha P Shah, Rajesh Nair, Pankaj P Shah, Dhiren K Modi, Shrey, A Desai, Improving quality of life with new menstrual hygiene practices among adolescent tribal girls in rural Gujarat, India, Reproductive Health Matters. 2013;21:205-13.

14. Abdel-Hady, El-Gilany, Karima Badawi, Menstrual Hygiene among Adolescent Schoolgirls in Mansoura, Egypt, Reproductive Health Matters. $2005 ; 13 ; 147-52$.
15. Enu Anand, Jayakant Singh, Sayeed Unisa, Menstrual hygiene practices and its association with reproductive tract infections and abnormal vaginal discharge among women in India, Sexual Reproduct Health. 2015;6:249-25.

Cite this article as: Wagh RV, Upadhye AJ, Upadhye JJ. Menstrual hygiene practices in young girls of urban India. Int J Reprod Contracept Obstet Gynecol 2018;7:1897-902. 